\title{
Interpreting Embodied Mathematics Using Network Theory: Implications for Mathematics Education
}

\author{
ELIZABETH MOWAT \\ University Of Alberta (Canada) \\ BRENT DAVIS \\ University of Calgary (Canada)
}

\begin{abstract}
Working from the premise that mathematics knowledge can be described as a complex unity, we develop the suggestion that network theory provides a useful frame for informing understandings of disciplinary knowledge and content learning for schooling. Specifically, we use network theory to analyze associations among mathematical concepts, focusing on their embodied nature and their reliance on metaphor. After describing some of the basic suppositions, we examine the structure of the network of metaphors that underlies embodied mathematics, the dynamics of this network, and the effect of these dynamics on mathematical understanding. Finally, implications for classroom teaching and curriculum are discussed. We conjecture that it is both instructive and important to use the network structure of mathematical knowledge to shed light on both cognition in mathematics and on mathematics education.
\end{abstract}


"Some of the deepest truths of our world may turn out to be truths about organization, rather than about what kinds of things make up the world and how those things behave as individuals." (Buchanan, 2002, p. 19)

\section{Introduction}

Throughout the history of modern schooling, mathematical pedagogy has been organized around prevailing beliefs regarding the nature of mathematical knowledge. Descartes's view of mathematics as a rigid and logical structure helped to give shape to linear curricula formulated around assumed-to-be-basic concepts that were elaborated incrementally and hierarchically. Analogously, the work of the Formalists in the early twentieth century was taken up in North America within the New Math Curriculum as a focus on axioms, laws and proofs.

As a new development in mathematics, arising in the last decade or so, the field of network theory may present a novel way of understanding the structure of mathematics and, in consequence, of informing pedagogy. Briefly, network theory examines the various ways in which a group of objects can be connected in some fashion. Originally developed as a branch of applied mathematics (specifically, an extension of graph theory), techniques developed in network theory have been employed to analyze diverse complex systems in nature, society, and business. The significance of the field lies in the finding that the conclusions of network theory arise from the underlying structure and topology of a complex system rather than from the particular objects that it comprises.

In the late 1990s, researchers began to develop the field of network theory as a means to explore the structural dynamics of the networks underlying complex systems. Specifically, their foci were the interactions among the system's agents, rather than the entities themselves or their specific characteristics. Viewing the elements of a system as nodes in a network and their interactions as links among nodes, the system of entities and their connections can be portrayed by a graph. Using this technique, Watts and Strogatz (1998) and Barabási and Albert (1999) identified patterns not previously seen in complex phenomena and formulated simple, yet comprehensive, laws that describe network structure and evolution. Scientists in many disciplines, ranging from physics to sociology, have found these principles invaluable in explaining how and why complex systems behave as they do.

Although the use of network theory in analyzing complex systems is rapidly expanding, it has not been applied to the field of mathematics education. It would seem to be desirable that educators be aware of these powerful and comprehensive methods of analysis. Knowledge and techniques developed for analyzing and understanding network behavior in other disciplines can be applied to the problems of education, providing teachers with a different way of thinking and perhaps helping them to answer questions about complex educational systems that have proved intractable to date.

In this paper, we begin by developing the suggestion that mathematics might be understood as a complex unity. That is, informed by the transdisciplinary realm of complexity science, we argue that mathematics is a dynamic, evolving form that 
manifests properties that are typical of those studied by complexivists. We open with this point because, as Cilliers (1998) argues, "a complex system is constituted by a large number of ... units forming nodes in a network with a high degree of non-linear connection" (p. 91). We suggest that cognitive mechanisms described in the theory of embodied mathematics, as put forth principally by Lakoff and Núñez (2000), form a network structure that offers an appropriate and useful model of mathematical knowledge. Our intention is not to explain how collective knowledge emerges; instead, we explore the structure and dynamics manifest in a knowledge domain. The next section of this paper describes certain important aspects of the theory of embodied mathematics. Subsequently, we explore how certain cognitive mechanisms described in this theory can be seen to constitute a network, which we refer to as the metaphoric network of mathematics. The topology and dynamic behavior of this structure are then examined. Finally, we suggest some curricular and pedagogical implications of our network analysis for school mathematics.

\section{Mathematics as a Complex System ${ }^{1}$}

In the last half of the $20^{\text {th }}$ century, there was a confluence of interest among a group of scientists drawn from many fields who began to realize that the phenomena they studied, while tremendously varied, had some deep commonalities. It was noted, for example, that anthills, brains, and cities seemed to obey analogous dynamics and to have structures that were oddly reminiscent of one another (cf., Johnson, 2001). This realization of common interest prompted the discourse field of complexity, finding similarities in many phenomena in which the autonomous interactions of multiple entities lead to coherent collective behavior. The abilities and potentials exhibited by these systems are different from and far more sophisticated than those possessed by the agents themselves. The study of complex systems - from collections of neurons in the brain to the interactions of species in an ecosystem - attempts to explain how such coherent and seemingly purposive wholes can emerge out of the apparently independent actions of individuals.

Because of the very involved and ever changing nature of interactions among such entities, complex systems cannot be described easily. Despite this, Cilliers (1998) suggests that general characteristics of complex forms can be identified, based on his survey of the complexity literature. In particular, he sees ten qualities as necessary to complex systems:

(i) Complex systems consist of a large number of elements....

(ii) The elements in a complex system interact dynamically....

(iii) The level of interaction is fairly rich. ...

\footnotetext{
${ }^{1}$ We have directed this paper to several different audiences, including complexivists and mathematics educators. For those who can readily accept that mathematics is a complex system, it may not be necessary to read this section of our argument. For others, new to the area, it may serve as a useful primer on the nature of complex systems.
} 
(iv) Interactions are non-linear. ...

(v) The interactions have a fairly short range. ...

(vi) There are loops in the interconnections. ...

(vii) Complex systems are open systems. ...

(viii) Complex systems operate under conditions far from equilibrium....

(ix) Complex systems have histories. ...

(x) Individual elements are ignorant of the behavior of the whole system in which they are embedded. ... (Cilliers, 1998, p. 119-123)

Cilliers (1998) posits that any system possessing these properties can be analyzed in terms of a neural-network model, originally developed from comparisons to the human brain (e.g., Edelman, 1987; Rumelhart \& McClelland, 1986). He demonstrates how this model can be used in analysis of postmodern society and suggests that it may also be appropriate for examining language and scientific knowledge. We attempt here to show that mathematics also possesses the requisite characteristics of complex systems and that, in consequence, a network model of mathematics is meaningful.

\section{(i) Mathematics consists of a large number of elements}

At first sight, it might seem that this claim requires no justification or elaboration. However, it is important to be clear as to the nature of the elements, which varies according to how one defines mathematics. For example, if defined as "what mathematicians do", it would seem that the interacting elements are individuals. Conversely, if defined in terms of the contents of a standardized examination, the elements might be taken to be discrete technical competencies. In this article, we argue that mathematics comprises a large number of ideas or concepts; these are the elements of the complex unity of mathematics. In imposing this sort of definition, however, we are compelled to acknowledge that it represents an artificial and ultimately untenable delimitation - but, nonetheless, a necessary one. As complexivists develop, complex systems do not have fixed or tidy edges. They intersect with, subsume, and are embedded in other complex unities. Hence, any study of a specific complex unity inevitably entails an imposition of some sort of artificial boundaries on the part of the observer.

(ii) The elements in mathematics interact dynamically

Pickering (1995) comments that practice in mathematics is "organized around the production of associations, the making of connections and the creation of alignments between disparate ... elements" (p. 22). Of course, few would argue with the suggestion that mathematical ideas interact; the critical point here is that they interact dynamically rather than coming together to form some sort of rigid architecture. Each idea informs and influences others in a constant choreography of emergent meaning. Thus, as mathematics historian Bell (1945) describes change in the system, some ideas die if they 
prove to be trivial, inadequate, or incorrect, while others survive, often with modification to ensure coherence with other concepts.

\section{(iii) The level of interaction among concepts in mathematics is fairly rich}

Relationships among concepts are rich and complex. New mathematical concepts are formed from interactions among those already existing (Hersh, 1998). These novel ideas may enrich established mathematical knowledge, and may, in turn, interact with other concepts to spur the development of new areas of mathematics (Struik, 1987). Mathematicians have developed a number of means to enable these rich interactions of ideas. As Rotman (2000) notes,

... it would be perverse not to infer that for large stretches of time [mathematicians] are engaged in a process of communicating with themselves and one another; an inference prompted by the constant presence of standardly presented formal written texts (notes, textbooks, blackboard lectures, articles, digests, reviews, and the like) being read, written, and exchanged, and of all informal signifying activities that occur when they talk, gesticulate, expound, make guesses, draw pictures, and so on. (pp. 7-8)

Such communication ensures that each piece of mathematical knowledge influences and is influenced by many other ideas.

\section{(iv) Interactions in mathematics are non-linear}

There are two aspects to the non-linearity of complex unities. The first has to do with the manner in which systems unfold through time. Within complex unities, certain perturbations can prompt unpredictable consequences. Thus, a small idea may spark large-scale changes in the system of mathematical knowledge as a whole. For example, Fermat and Pascal's discussion of a game of chance in 1654 led to the formation of the theories of probability and statistics (Bell, 1945).

The second aspect of non-linearity involves potentially asymmetrical relations among elements as they interact in the moment. For example, a concept may be associated in different ways with different ideas. Analogous to the way in which the relationship of "red" to "blue" is not similar to its relationship to "blood" (Cilliers, 1998), the relationship of $\sin \theta$ to $\cos \theta$ and $\tan \theta$ is not the same as its relation to the integral or the power series.

\section{(v) Interactions among mathematical concepts have a fairly short range}

Most mathematical ideas interact primarily with the other elements of their particular subfield of mathematics; basic concepts commonly used in one area may be completely foreign to another (Thurston, 1994). Such relatively local ideas may play an important role in providing specific instances that lead to the formulation of generalizations in a subfield (Bell, 1945).

However, as Cilliers (1998) notes, "despite the short range of immediate interactions, nothing precludes wide-ranging influence" (p. 121). Ideas, such as set theory, permeate many branches of mathematics and, in the process, provide a unifying structure. Other 
long-range interactions may lead to novel concepts in mathematics. For example, the connections between algebra and geometry, made in efforts to give meaning to complex numbers, led to the development of alternate algebras and foreshadowed modern vector analysis (Pickering, 1995).

\section{(vi) There are loops in the interconnections among mathematical ideas}

"Feedback is an essential aspect of complex systems. Not feedback as understood simply in terms of control theory, but as intricately interlinked loops in a large network" (Cilliers, 1998, p. 121). There are many examples of these interconnected loops in the history of mathematics, such as the deep connections involved in the emergence of number systems. For example, the sexagesimal positional notation used by Babylonians may have influenced the development of the decimal system (Cajori, 1896). This more efficient numeric system, in turn, led to a decline in the use of the earlier notation for most purposes. Another instance took place as work with sets led to the development of Russell's Paradox and Gödel's Incompleteness Theorem. These results forced the reexamination of the entire field; set theory was not discarded, but was reshaped in the search for a foundation of mathematics (Hersh, 1998). Thus, loops in the interconnections among mathematical concepts can affect both the survival and the meaning of those ideas.

\section{(vii) Mathematics is an open system}

Mathematics is constantly bombarded with input from its physical, cultural and intellectual environment. Thus, the conceptual content of mathematics is influenced by other fields, from astronomy and agriculture in ancient times to psychology and physics today (Struik, 1987).

\section{(viii) Mathematics operates under conditions far from equilibrium}

One of the challenges to commonsense belief presented by complexity thinking is the assertion that living and learning forms do not seek or operate in equilibrium (Kelly, 1994). Rather, they exist in imbalance and cannot survive in a static condition. Examination of the history of mathematics reveals that the discipline is not fixed (cf., Bell, 1945; Struik, 1987), but "evolves by rather organic ... processes" (Thurston, 1994, p. 347). As with any evolving system, changes in mathematics may occur in a sequence of small steps or through major revolutions (Grabiner, 1998). Its openness to external influences and the many loops in interactions among its elements ensure that the system of mathematical concepts is not at equilibrium, but continually changes.

\section{(ix) Mathematics has a history}

Mathematics has a history and mathematical concepts carry with them bits of their past. Residues of once commonly used notions can be seen in notation, terminology, and procedures (Bell, 1945). Such traces persist long after the original idea has been changed 
beyond recognition. Thus, the meaning of a mathematical concept is dependent on both its past and its present interactions with other elements of mathematics.

\section{(x) Individual elements are ignorant of the behavior of the whole system in which they are embedded}

Since the $19^{\text {th }}$ century, mathematics has been splintered into many specialized fields (Struik, 1987; Thurston, 1994). Consequently, concepts interact primarily with ideas that lie within the same branch of mathematics, that is, they respond to relatively local information. While exceptionally involved, it is unlikely that a concept could reflect the complexity of the subfield, much less the entire system of mathematics. Therefore, it would seem that the complexity of mathematics, as with any other complex system, is "the result of a rich interaction of $\ldots$ elements that only respond to the limited information each of them are presented with. ... The complexity emerges as a result of the patterns of the interaction between the elements" (Cilliers, 1998, p. 5).

Given that mathematics appears to manifest the defining characteristics of complex systems set forth by Cilliers (1998), it would seem reasonable to consider it as a complex unity. While we realize that this point has not been demonstrated conclusively, we proceed here under the assumption that it is appropriate to use a neural network as a model for mathematics in general, and, more specifically, for related systems involved in mathematics education.

Like other complex phenomena, educational systems might be argued to be forms nested in and interacting with other forms (Davis \& Simmt, 2006). Subjective understanding can be viewed as being embedded in the collective knowledge of the classroom, which in turn is part of knowledge of mathematics as portrayed in a curriculum, itself positioned in the system of formal mathematics (see Figure 1). ${ }^{2}$ Each layer simultaneously enables and constrains the others.

As noted, our principal focus in this paper is mathematics understood as a system of ideas or concepts. However, we suggest that the description offered and the implications developed are relevant not just to the formal knowledge of the discipline of mathematics (the outer nested layer of Figure 1), but also to the personal knowing of individual learners (the inner nested layer of Figure 1). Changes in structure occur at both levels, but at vastly different rates; networks of formal mathematical concepts are transformed very slowly as new conjectures are gradually developed and adopted by communities of mathematicians, while modifications may occur quite quickly as students construct their own understanding of topics new to them. In spite of these differences, Davis and Simmt (2006) suggest that drawing a clear distinction between what Cooney and Wiegel (2003) term "fixed" and "constructed" mathematics is perhaps problematic.

\footnotetext{
${ }^{2}$ As noted earlier, we recognize that the categories of complex identities in this diagram are shaped by the specific observers' perspectives. We further acknowledge that, as with all attempts to represent complexity, the structure and dynamics of these phenomena have been drastically simplified.
} 


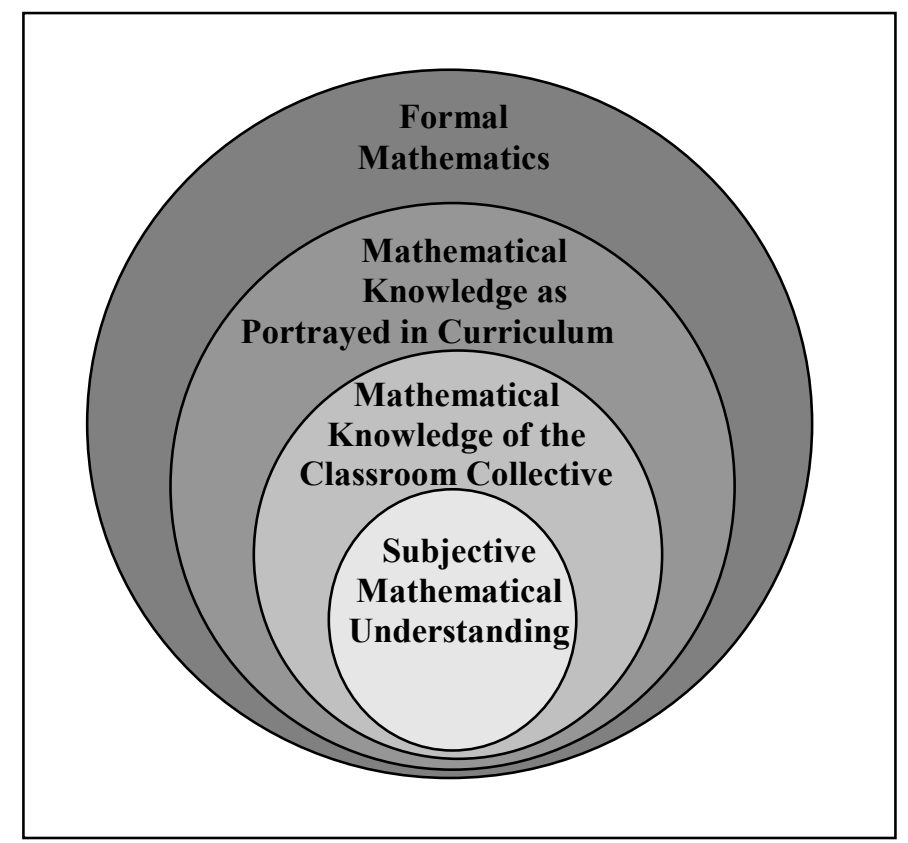

Figure 1: Some dynamic co-evolving complex phenomena of concern to the mathematics teacher (adapted with permission from Davis \& Simmt, 2006).

We suggest that employing networks to represent both mathematical understanding at the subjective level and mathematical knowledge as a field of study (the inner and outer nested forms in Figure 1) may shed new light on mathematical cognition. Moreover, since each level in a system of nested forms both makes possible and restricts the others, new perceptions resulting from the use of network theory at these levels may assist in understanding other forms in the nested system shown in Figure 1. Therefore, a network theory analysis may assist mathematics educators to gain valuable guidance for the generation of collective knowledge in classrooms and in the organization of mathematical knowledge as portrayed in curricula (the two middle layers of Figure 1).

We should comment here that, unlike the work done by complexivists in many fields, our paper does not include the mathematical analysis of a network structure. Early studies using network theory tended to focus on simple (often random) mathematical models. Later, network theorists began to describe the properties of real world networks as observed in collected data (Newman, Barabási \& Watts, 2006). We have not developed a mathematical model, nor do we have empirical data to analyze. Instead, we offer a possible model for the structure of mathematical knowledge and explore it, looking for the defining characteristics of network representations of complex systems (cf., Barabási, 2003; Watts, 2002).

We posit that a possible network structure for mathematical knowledge may be found in the conceptual domains and conceptual metaphors presented in the theory of embodied mathematics, specifically the version put forth by Lakoff and Núñez (2000). In the discussion that follows, we will argue that using such cognitive mechanisms as components of a network for mathematics offers an appropriate and fruitful foundation for analysis of mathematical structure. In developing this suggestion, and following 
Stewart's (1998) observation that mathematics has been recast as a source of possible models rather than a compendium of actual explanations, we work from the assumption that the accounts offered by the theory of embodied mathematics and by network theory (or any other discourse domain) should be treated in terms of a useful interpretation or analogy for the structure of mathematics rather than a definitive description.

\section{The Theory of Embodied Mathematics ${ }^{3}$}

Lakoff and Núñez (2000) conceive of mathematics as being extended from a rather limited set of inborn skills through bodily experiences to an ever-growing web of conceptual domains. These are connected by conceptual metaphors - cognitive mechanisms used automatically and unconsciously - which abstract patterns of inference from physical experience. Grounding metaphors make basic arithmetic possible by forming correlations between innate abilities and physical actions like "forming collections, putting objects together, using measuring sticks, and moving through space" (Lakoff \& Núñez, 2000, p. 102). Other conceptual metaphors link arithmetic to more abstract mathematical concepts, each metaphor carrying inferential structure systematically from one domain to another. New concepts are formed as domains fuse and create conceptual blends; new metaphors involving these blends are subsequently formed. This "network of ideas" is the basis of mathematical knowledge and knowing (Lakoff \& Núñez, 2000, p. 376).

Although it is not clear that Lakoff and Núñez mean to evoke the mathematical discipline of network theory with this phrase, we would contend that closer examination of the structure of conceptual domains in terms of networks should shed light on both subjective understanding of mathematics and the formal structure of mathematical objects (the inner and outer nested layers of Figure 1). In education, as with other complex phenomena, "what happens and how it happens depends on the network" (Watts, 2002, p. 28).

\section{The Metaphoric Network of Mathematics}

While Lakoff and Núñez (2000) describe the mechanism by which the network of metaphors in mathematics is developed, they do not talk about its structure as a formal network. Knowledge of the topology of this network would enable the system of metaphors and concepts to be understood as a whole (Barabási, 2003). The nature of the nodes in the network and the links that connect them are key in determining this structure.

\footnotetext{
${ }^{3}$ Much of our discussion in this paper is organized around the ideas of Lakoff and Núñez (2000). This section is intended to provide needed background for those readers not familiar with their work.
} 


\section{Conceptual Domains as Nodes}

We propose to take, as the nodes of the metaphoric network of mathematics, conceptual domains like the CONTAINER IMAGE SCHEMA, ${ }^{4}$ ARITHMETIC, or FUNCTION. ${ }^{5}$ Even the simplest of these domains possesses considerable internal structure (Johnson, 1987). Each domain contains interconnected elements forming a complex of sensory experiences, language, and related concepts. Thus, each conceptual domain is a subnetwork of the larger network that forms the cognitive system (Kimmel, 2002; Kövacses, 2002; Lamb, 1999). Nodes are not just basic units, but should be understood as subnetworks in themselves.

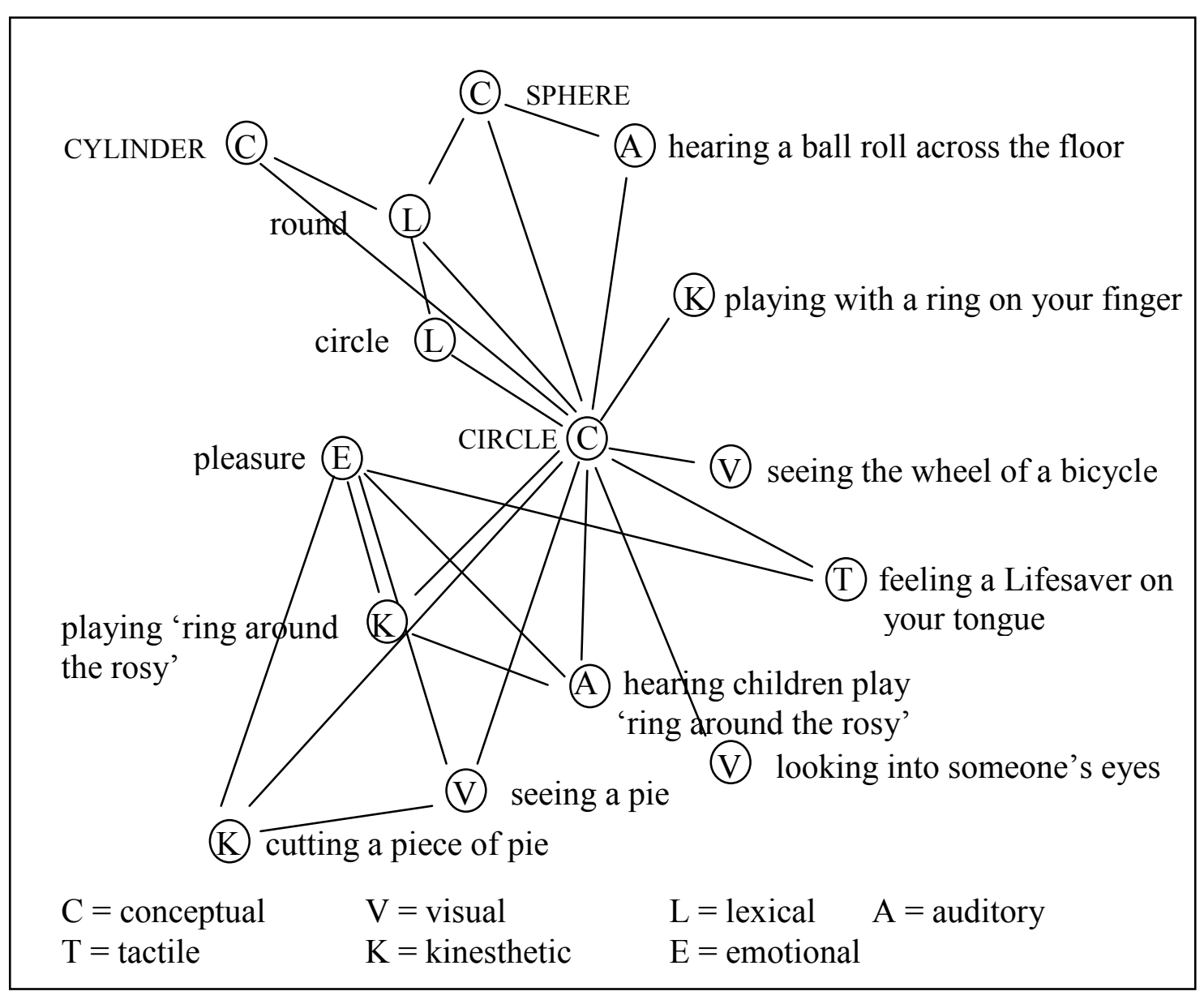

Figure 2: Part of the conceptual CIRCLE following Lamb's (1999) example of CAT

\footnotetext{
${ }^{4}$ An image schema is a primitive, embodied cognitive mechanism based on spatial relations, which establishes patterns of understanding and reasoning. These pre-linguistic structures appear to be universal (Lakoff \& Núñez, 2000).

${ }^{5}$ Throughout the paper, we follow the convention of identifying conceptual domains, conceptual metaphors, and other cognitive mechanisms by using small capitals.
} 
For example, a conceptual domain like CIRCLE contains many nodes representing a person's knowledge of and experiences with circles, all held together by a central coordinating conceptual node (Lamb, 1999). This network is dynamic, changing with new experiences and interpretations, and differs from person to person. Figure 2 illustrates only part of a potential network for CIRCLE: it is not possible to provide a complete map, for any concept may contain thousands of nodes (Lamb, 1999). When sensori-motor, lexical, and conceptual nodes in the domain labeled CIRCLE are activated, they operate together in gestalt and form an individual's perception of circles (Lakoff, 1987; Lakoff \& Núñez, 2000; Lamb, 1999). A node like the visual node labeled "seeing a pie" in Figure 2 is itself a subnetwork of the conceptual domain (Lamb, 1999). It includes the many different visual features (color, size, type) that might be involved in a person "seeing a pie".

Patterns of inferential structure used in mathematics also have their own network structure. Figure 3 presents some of the physical, spatial logic, lexical, and conceptual nodes that constitute part of the network an individual might construct for the domain representing the CONTAINER IMAGE SCHEMA, which is highly important for reasoning in mathematics (Lakoff \& Núñez, 2000).

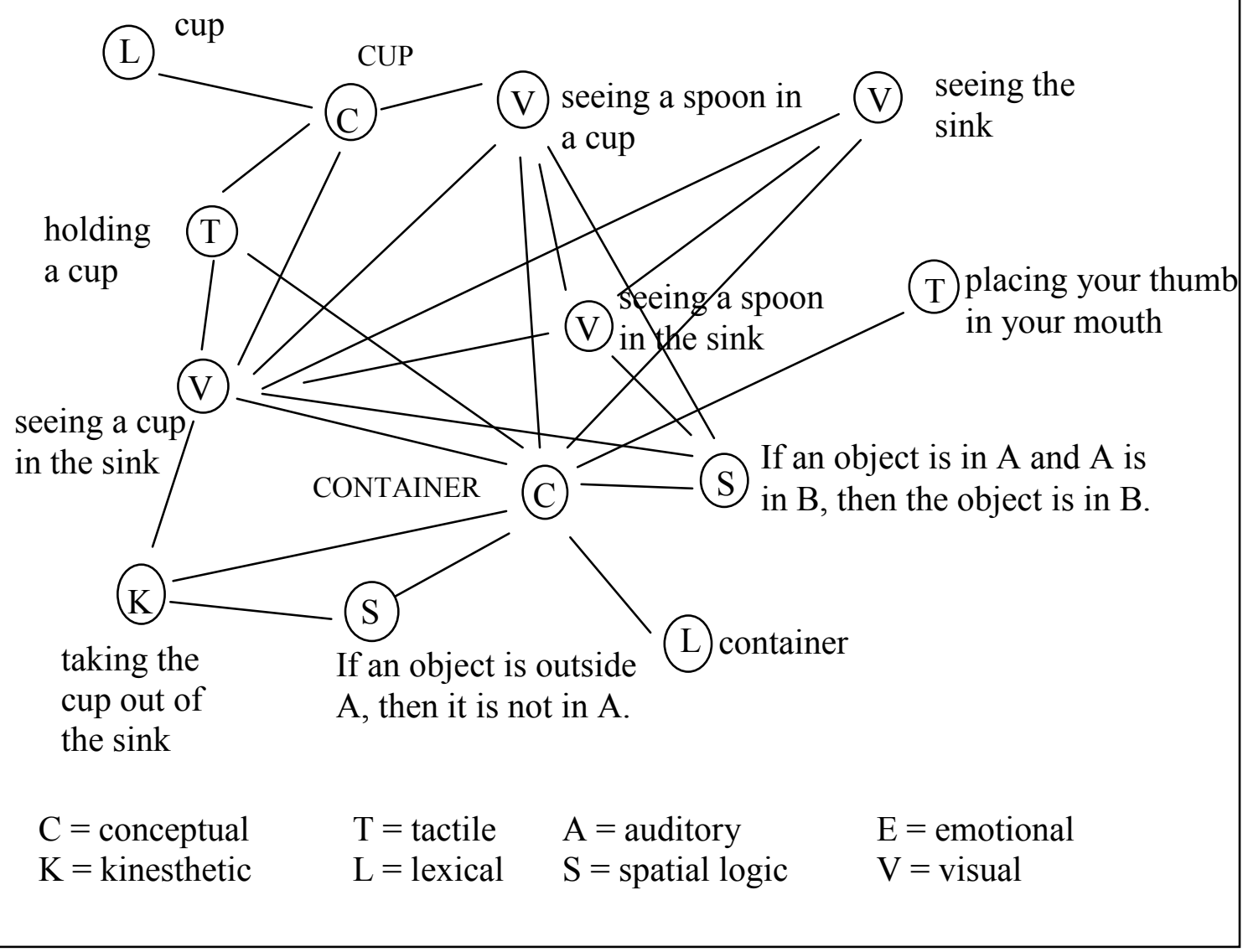

Figure 3: Part of the CONTAINER IMAGE SCHEMA 
Not all of the nodes in a conceptual domain must be stimulated in order to awaken this gestalt. "For most ... concepts there are many properties, and if enough of them are present in a given situation, the [concept] is activated" (Lamb, 1999, p. 154). Thus each concept has a threshold of activation; this is the number of nodes, not all of equal weight, that must become functional in order to trigger the domain. For some concepts, the threshold may be one. The sound of a ball rolling, for instance, might be enough to stimulate the central conceptual node for CIRCLE and, through it, the rest of the nodes in the subnetwork. Other domains may have higher activation thresholds. There is no simple way of determining how many properties need to be satisfied for a conceptual domain to become active (Lamb, 1999).

\section{Conceptual Metaphors as Links}

Lakoff and Núnez (2000) suggest that the links between conceptual domains are conceptual metaphors. These cognitive mechanisms "allow us to reason about relatively abstract domains using the inferential structure of relatively concrete domains" (Lakoff \& Núñez, 2000, p. 42). Conceptual metaphors are referential systems of thought; metaphoric expressions in language and gesture are simply surface manifestations of an underlying conceptual metaphor (Lakoff, 1993; Núñez, 2004).

Particular features from one domain (the source) are mapped onto corresponding aspects of another domain (the target) by such conceptual metaphors. Grounding metaphors link arithmetic domains to sensori-motor experiences. The ARITHMETIC IS MOTION ALONG A PATH ${ }^{6}$ metaphor links the source domain of the physical experience of moving in a line from one location to another to the target domain of arithmetic. Less concrete metaphors, like A NUMBER IS A SET, link one abstract mathematical concept to another. Still others (see Figure 4) enable features of different concepts to combine in a new domain (a conceptual blend); ARITHMETIC IS MOTION ALONG A PATH can be blended with ROTATION BY $180^{\circ}$ to form a conceptual blend that accounts for MULTIPLICATION BY A NEGATIVE NUMBER (Lakoff \& Núñez, 2000). ${ }^{7}$

Not all characteristics of the source domain are mapped onto the target domain. It is typical of a metaphor that it has "unused parts" (Lakoff \& Johnson, 1980); if aspects of a source domain do not correspond to some portion of the target domain, they will simply not be mapped on to it (Kövacses, 2002). Those conceptual materials from the source domain that are projected onto a target are not chosen arbitrarily, but are tightly constrained by the nature of the body and the brain, and by interactions with physical and social environments (Lakoff \& Johnson, 1999; Kövacses, 2002).

\footnotetext{
${ }^{6}$ Metaphors will be identified using the convention 'TARGET' IS 'SOURCE'.

${ }^{7}$ We acknowledge that many examples used in this paper were originally developed by mathematicians in the past. For example, the image of multiplication by -1 as a rotation through $180^{\circ}$ on the number line contributed to Jean Robert Argand's conception of $i$ as a rotation through $90^{\circ}$ in 1806 ( $\mathrm{O}^{\prime}$ Connor \& Robertson, 2000). We thank John Mason for bringing this to our attention.
} 


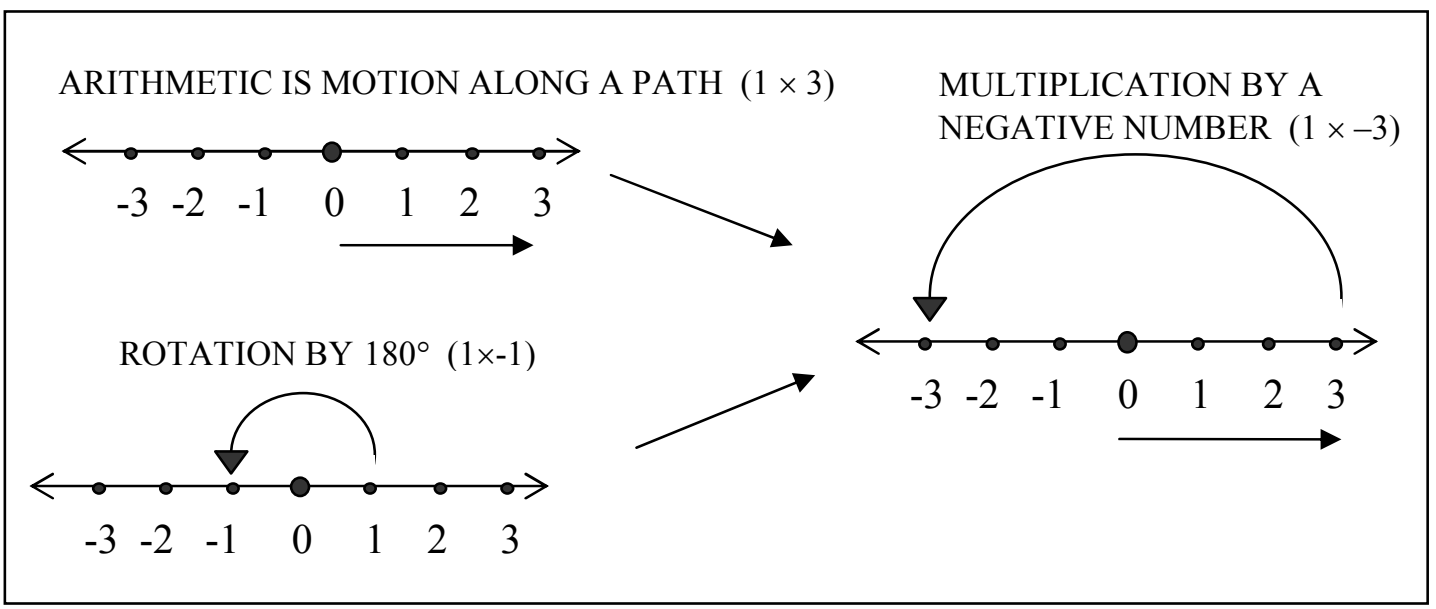

Figure 4: The conceptual blend for MULTIPLICATION BY A NEGATIVE NUMBER

For many important conceptual domains, a single metaphor does not provide enough structure to depict the concept as a whole (Lakoff \& Johnson, 1999). More than one source is required to illuminate such rich domains, each metaphor describing a different aspect of the complex target (Kimmel, 2002; Kövacses, 2002). Together, metaphors with a common target can construct a coherent understanding of the domain (Lakoff \& Johnson, 1980); each metaphor enables an alternative interpretation of the target domain in a different context (Kimmel, 2002). For example, LOVE is the target domain for a multitude of metaphors, some of which are listed in Figure 5 (Kövacses, 2002; Lakoff \& Johnson, 1980).

LOVE IS A JOURNEY

LOVE IS A NUTRIENT

LOVE IS INSANITY

LOVE IS MAGIC

LOVE IS WAR

LOVE IS A FORCE
We'll just have to go our separate ways.

I'm starved for love.

I'm crazy for her.

She's got me under her spell.

He's captured my heart.

He knocked me off my feet.

Figure 5: Some of the metaphors for the target domain LOVE

Just as target domains may be metaphorically linked to more than one source, many source domains provide a framework for a variety of targets (Kövacses, 2002). The concept of BUILDING has three underlying components: the construction of a building; the physical structure of a building; and the stability or strength of a building. Metaphors that use BUILDING as a source (see Figure 6) transfer these features and consequent dynamics to the target domains (Kövacses, 2002). 
A THEORY IS A BUILDING

A RELATIONSHIP IS A BUILDING
I have to put my thoughts together.

He had a strong argument.

His theory had a solid foundation.

They built a good relationship.

Nothing can shake our love.

Our friendship is based on common interests.

Figure 6: Some metaphors using BUILDING as a source domain

A conceptual domain may be used deliberately as the source for different metaphors to develop a common structure for disparate target domains. The metaphors AN ORDERED PAIR IS A SET and A NUMBER IS A SET are used to express all of mathematics in terms of set theory (Lakoff \& Núñez, 2000). Because metaphors preserve inferential structure, appropriate modes of reasoning can be mapped onto both ordered pairs and numbers - a move that enabled the work done by the foundationalist philosophers of mathematics in the early-1900s.

While typically considered to be directional mappings from source domain to target domain (Lakoff \& Núñez, 2000), metaphors do not always project inferential structure in just one direction (Danziger, 1990; Meisner, 1992). Over time, conceptual metaphors may become bidirectional; the target domain gradually comes to be viewed as a source (Kimmel, 2002), changing understanding of the original source domain or domains that shaped it (English, 1997; Sfard, 1997). This is most likely to occur when the target is structured by more than one source domain (Meisner, 1992).

For example, ARITHMETIC is grounded in OBJECT CONSTRUCTION; the metaphor is revealed in turns of phrase like " 2 plus 3 makes 5 " and " 6 can be broken up into 3 groups of 2 ". Such expressions show how experiences constructing objects affect our thinking about arithmetic and numbers. These modes of thought, in turn, change how other source domains for ARITHMETIC, such as MOTION ALONG A PATH are perceived; we speak of "breaking a journey up into three easy stages". Something of our experience constructing objects that has been mapped onto the domain of ARITHMETIC is subsequently projected onto the MOTION ALONG A PATH domain. A conceptual metaphor, like ARITHMETIC IS MOTION ALONG A PATH, does not project structure in just one direction, but involves "ceaseless two-way interaction between the old and the new ... [in a] process of coemergence" (Sfard, 1997, p. 355).

\section{The Topology of the Metaphoric Network of Mathematics}

Cognitive mechanisms offer a possible network structure for mathematics, with conceptual domains (nodes) connected to each other in complex ways by conceptual metaphors (links). Nested within this formation, subnetworks represent a multitude of sensory perceptions, linguistic forms, and other relationships for each concept. A closer look at such a concept's subnetwork reveals yet more deeply embedded structures, like 
the sensori-motor network that might represent the many different aspects of a particular tactile perception. Figure 7 offers an image of this nested organization, which is typical of complex systems (Davis \& Simmt, 2006).

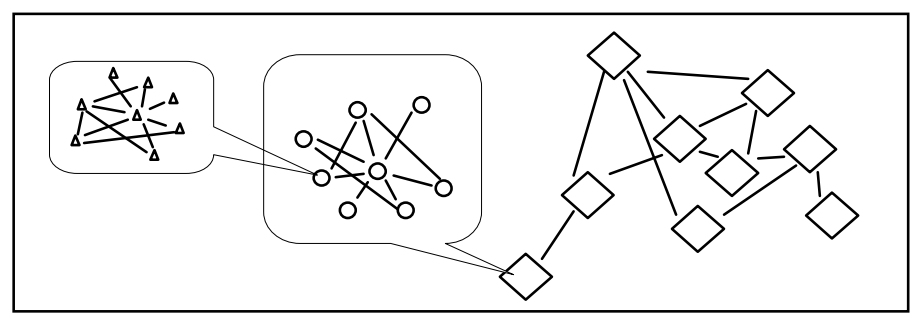

Figure 7: A subnetwork (perhaps of the many tactile features involved in "holding a cup") nested within the subnetwork of the CONTAINER IMAGE SCHEMA domain (see Figure 3), which is itself nested within the metaphoric network of mathematics.

Networks representing real complex systems also tend to display a scale-free topology (Barabási, 2003; Watts, 2002). In this type of structure, clusters are formed within which every vertex is connected to a key node; these hubs are in turn linked to more central nodes, and so on (see Figure 8). While a few nodes are very highly connected, most are linked to only a few other vertices. Thus, it is not meaningful to determine a scale or typical number of links for nodes in the network.

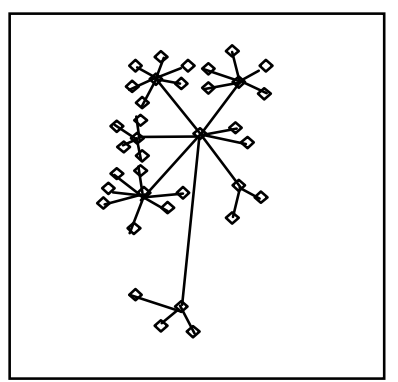

Figure 8: A simple network displaying a scale-free topology

Much research has been done investigating complex systems exhibiting scale-free topology. Barabási and Albert (1999) state that necessary and sufficient conditions for this structure are growth and preferential attachment. The metaphoric network of mathematics appears to possess these attributes and, thus, to exhibit the structure of a scale-free network.

Growth: How nodes are formed, modified and reorganized

The network of conceptual domains linked by conceptual metaphors provides a possible structure both for the mathematical understanding of individuals and for mathematical knowledge as a formal discipline. Systems at both these levels are not static, but expand as new nodes come into being, as existing nodes change, and as new links between nodes are formed. 
On the subjective level, image schemas are first developed as infants respond to their world (Johnson, 1987). These cognitive mechanisms are used repeatedly "as scaffolding for [a] ... growing conceptual system" (Sfard, 1997, p. 350). Conceptual metaphors project inferential structure from concrete and familiar domains to create more abstract concepts (Lakoff and Johnson, 1999). Learners are introduced to conceptual metaphors from many sources - parents, peers and teachers. Many exegetical metaphors, that is, metaphors used for schooling, like AN EQUATION IS A BALANCE, play an important role in assisting people to learn mathematical concepts needed for every-day routines and to acquire the mathematical competencies necessary for becoming part of the larger mathematics community (Travers, 1996). Teachers and students may also construct idiosyncratic metaphors, relating newly encountered concepts to their own personal experiences (Presmeg, 1992; Sinclair \& Schiralli, 2003). ${ }^{8}$ Metaphors from all these sources both bring new concepts into being and modify existing domains.

The discipline of mathematics also grows through cognitive mechanisms. Entailments of metaphors can lead to new understandings of previously encountered conceptual domains and to the development of new concepts. For example, the MEASURING STICK METAPHOR portrays numbers as physical segments (Lakoff \& Núñez, 2000). Using this metaphor, anything that can be measured - not just using a ruler or other rigid item, but with any device, perhaps a measuring tape - can be considered a number; this provides some inferential structure for a previously unknown domain, the irrational numbers (see Figure 9). ${ }^{9}$

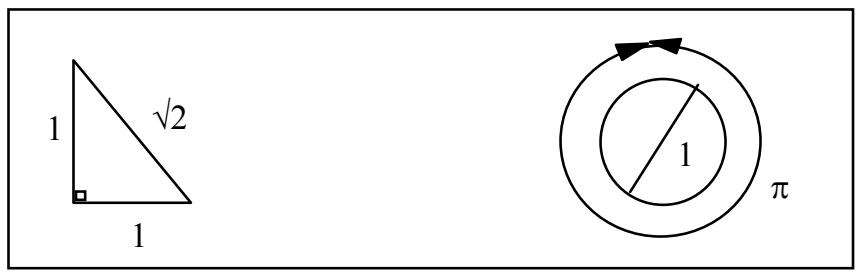

Figure 9: Grounding $\sqrt{2}$ and $\pi$ using the MEASURING STICK METAPHOR

8 There is some controversy about the difference between the conceptual metaphor and the idiosyncratic metaphor. Many researchers characterize the conceptual metaphor as a "publicly accessible tool" (Sinclair \& Schiralli, 2003, p. 5) and contrast it to the idiosyncratic metaphor, "private, personal and ripe with meaning" (Presmeg, 1997, p. 277) that spontaneously evolves when an individual tries to make sense of mathematics on their own (Sinclair \& Schiralli, 2003; Sfard, 1997). But an idiosyncratic metaphor may in fact be a conceptual metaphor, that is, "a grounded, inference-preserving cross-domain mapping" (Lakoff \& Núñez, 2000, p. 6). For example, Machtinger (1965) creates a metaphor, GROUPS OF CHILDREN ARE NUMBERS, to assist kindergarten children in conjecturing and justifying theorems about number theory. The metaphor, while certainly idiosyncratic, is just as surely conceptual. Viewed from this perspective, the distinctions drawn between idiosyncratic and conceptual metaphors seem perhaps artificial.

${ }^{9}$ As one reviewer noted, "this begs the question of continuity and the existence of irrational numbers". 
Nodes are also added to the metaphoric network of mathematics through conceptual blends. These cognitive mechanisms construct a partial correspondence between two unrelated sources and project this onto the novel blended domain; the new concept possesses elements not found in either of the contributing domains (Fauconnier \& Turner, 1998; Lakoff \& Núñez, 2000). The UNIT CIRCLE is the conceptual blend of a circle in the Euclidean plane and the Cartesian plane with coordinate axes (see Figure 10). ${ }^{10}$ It possesses characteristics of both of these domains, but also has emergent properties related to trigonometry that are not found in either of the initial domains.

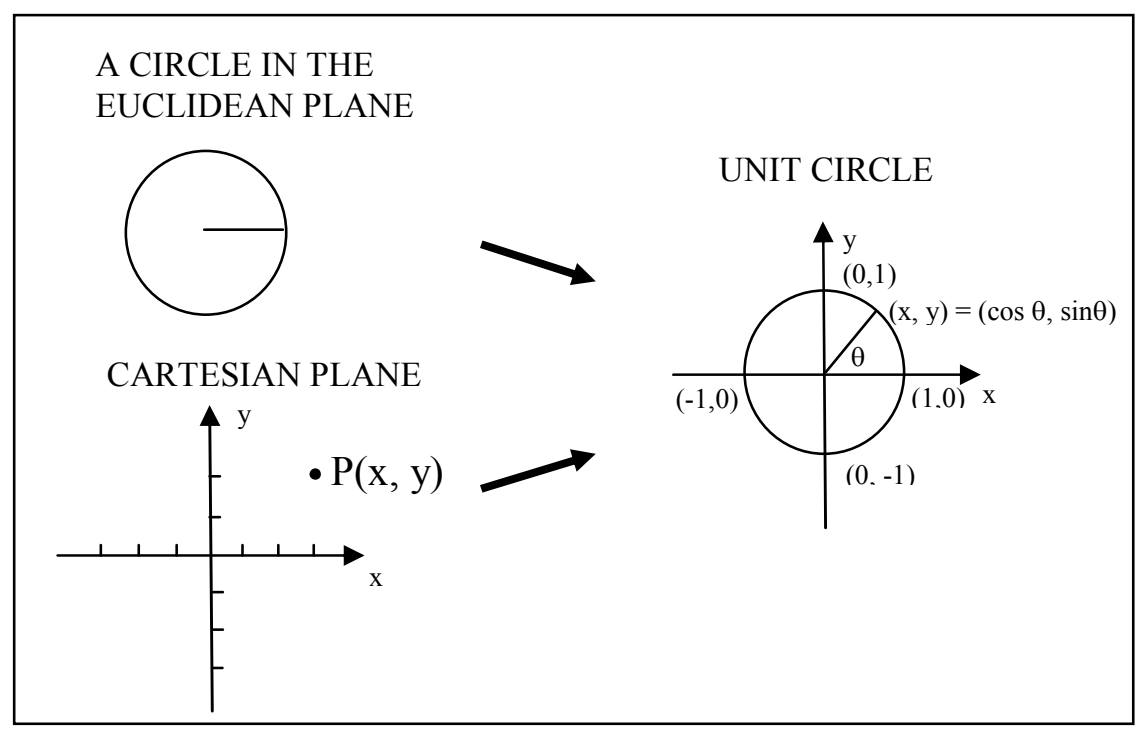

Figure 10: Features of Euclidean and Cartesian geometry combined into the UNIT CIRCLE

Most significantly, metaphors have the power to constitute previously unknown concepts; metaphoric mappings do not merely highlight a domain that already exists, but bring new concepts into existence by transplanting inferential structure from one context into another (Sfard, 1997). For example, the metaphor linking rotation by $90^{\circ}$ to $i$, which was used by Argand to give geometric meaning to complex numbers ( $\mathrm{O}^{\prime}$ Connor \& Robertson, 2000), is a classic use of this type of constitutive metaphor in mathematics.

While often ignored or hidden, the role that metaphor plays in the creation of new conceptual domains in the field of mathematics is sometimes recognized. Sfard (1994) quotes a mathematician who acknowledges the important function metaphor serves in his work:

To understand a new concept I must create an appropriate metaphor. A personification.

Or a spatial metaphor. A metaphor of structure. Only then can I answer questions, solve

\footnotetext{
${ }^{10}$ Figure 10 was our own attempt to illustrate the UNIT CIRCLE conceptual blend. Later, we discovered that it has a remarkable similarity to figures on pages 390-392 in Where Mathematics Comes From. Independent development of the diagram illustrates how particular metaphors have entailments that compel certain interpretations. It is likely that any graphic representation of the UNIT CIRCLE conceptual blend would closely resemble Lakoff and Núñez's images.
} 
problems. I may even be able then to perform some manipulation on the concept. Only when I have the metaphor. Without the metaphor I just can't do it. (p. 48)

Individuals develop understanding of new mathematical ideas through conceptual metaphors. Learners are introduced to exegetical metaphors in discourse and may develop their own idiosyncratic metaphors to assist in making sense of mathematical situations. The formal field of ideas that comprises mathematics can grow through entailments and extensions of existing metaphors, through constitutive metaphors that create new concepts, and through conceptual blends. At both the subjective and formal levels (the inner and outer nested layers of Figure 1), the metaphoric network of mathematics appears to satisfy the criterion of growth as new nodes are added to the network and as existing nodes are transformed and reorganized.

Preferential attachment: Why some nodes attract more connections.

As the metaphoric network of mathematics grows, nodes are added and new connections formed. Each node may be the target domain for projections from several sources, just as each domain may serve as the source for metaphors to a variety of targets. Perhaps unexpectedly, "if a source domain is used to shed light on one or more salient target domains ... this increases its likelihood to be chosen as a source domain in the future" (Kimmel, 2002, p. 108). When a concept is used as the source for a number of targets, it not only creates coherence among them by providing a common basis for their grounding, but it is strengthened in itself, simply because it is used repeatedly (Boyer, 1994). Recurrent use contributes to the source domain becoming a "cultural attractor of meaning" (Kimmel, 2002, p. 113) - a hub in the metaphoric network of mathematics.

Other factors may influence whether a source becomes an attractor of meaning. Nodes added to the network early in its development have had more time to acquire links (Barabási, 2003; Barabási, Albert, Jeong \& Bianconi, 2000). Thus, sensori-motor image schemas developed through early experiences may become hubs that are connected to a large number of concepts. For example, the CONTAINER IMAGE SCHEMA serves as the source domain for many metaphors (Lakoff \& Núñez, 2000).

Nodes that have a greater degree of "fitness" may be involved in more connections than other nodes (Bianconi \& Barabási, 2001). Thus the generalizability and flexibility of a conceptual domain may determine whether it becomes a hub in the network. Certain domains are repeatedly employed as sources because of the utility of their particular inferential structures. Their use as sources becomes not just acceptable, but traditional. History provides examples; soon after Cantor's development of set theory in the late 1800s, the domain of SET was commonly used as the foundation for newly developed concepts in many other branches of mathematics (Eves, 1997).

Thus, metaphors tend to link new concepts to domains that are already used as sources for a number of other conceptual metaphors. Both the "age" of a conceptual domain and its "fitness" determine whether a node is likely to attract new links. But other factors are certainly involved. People do tend to use sources that they are already familiar with; "in the end, we all follow an unconscious bias, linking with higher probability to the nodes we know which are inevitably the more connected nodes of the 
[network]" (Barabási, 2003, p. 85). As well, formal education might be understood in terms of reinforcing the use of commonly accepted metaphors. Whatever the cause, source domains with numerous links are likely to become even more well-connected, ensuring that the evolving network of metaphors in mathematics exhibits the property of preferential attachment.

The two features of growth and preferential attachment are the defining characteristics of a scale-free network topology (Barabási \& Albert, 1999). As the network of conceptual metaphors in mathematics exhibits these characteristics, it shares the "common blueprint ... [that governs] the structure and evolution of all the complex networks that surround us" (Barabási, 2003, p. 6).

\section{The Dynamics of the Network of Metaphors}

To understand a complex system it is necessary to consider more than network structure and topology; one must focus on the dynamics that take place along its links (Barabási, 2003). Knowing how a scale-free network operates is particularly important for the metaphoric network of mathematics as these dynamics have a significant impact on mathematical understanding.

The most significant feature of a scale-free network is the distribution of connectivity; most nodes have relatively few links to the rest of the network, but a few nodes have a great many connections (Barabási, 2003; Watts, 2002; see Figure 8). In the network of metaphors in mathematics, these hubs are the concepts to which other domains tend to be connected; that is, sources that are attractors of meaning and linked to many targets.

Such highly connected ideas provide a common basis for understanding the different concepts attached to it (Chiu, 2000). To illustrate and to consolidate some of the key notions involved to this point, the conceptual domain of SET is a $h u b$; as a source domain it is connected via links or conceptual metaphors (some of which are listed in Figure 11) to many target domains.
AN ORDERED PAIR IS A SET.
A FUNCTION IS A SET.
A NUMBER IS A SET.
A LINE IS A SET.
A LOGICAL PROPOSITION IS A SET.
A GRAPH IS A SET

Figure 11: Conceptual metaphors with a source domain of SET

Significant aspects of the inferential structure of SET (see Figure 12) are projected onto these nodes. These features with their dynamic interrelationships not only highlight similarities among target domains, but serve as a foundational system for much of mathematics. 
The elements of a set The intersection of sets A subset of a set The mapping of one set onto another
The complement of a set

The union of sets

The universe to which a set belongs

Figure 12: Part of the structure of the SET conceptual domain

Such extremely well-connected nodes have a critical effect on the overall behavior of the network. "Hubs create short paths between any two nodes in the system" (Barabási, 2003 , p. 64). In other words, the "distance" between different domains is reduced and interactions among them are facilitated.

However, if a network is made up of directional links, projecting structure in just one direction, communication within the network is limited (Barabási, 2003). While a one-way path from node A to node B may consist or 2 or 3 short steps, the reverse path from B to A may not even exist. The network is segmented into several distinct regions and interactions between these regions are restricted (Broder et al., 2000).

In the metaphoric network of mathematics, where at least some metaphors are bidirectional, the likelihood that the network is a unified structure rather than a collection of fragments is increased (Barabási, 2003). One might thus expect that any conceptual domain in mathematics can be linked to any other by a sequence of relatively few conceptual metaphors, a point that might be supported through reference to recent examinations of the figurative underpinnings of some mathematical concepts (cf., Lakoff \& Núñez, 2000; Mazur, 2003).

Such highly connected networks are generally very robust. Since the majority of nodes have only a few links, a significant number of nodes can be removed from the system with little or no effect. If a hub is compromised, however, a cascade of failures may cause the network to break into isolated fragments (Albert, Jeong \& Barabási, 2000; Barabási, 2003). Important links between clusters of nodes are lost. Thus, perturbation of such key nodes handicaps the whole system; all scale-free networks are vulnerable in this way (Barabási, 2003).

Perhaps the most significant consequence of the presence of hubs in a network is the possibility of a cascading failure. The weakening of a key concept or hub may reverberate throughout the network; nodes directly connected to the hub fail first, nodes linked to these fall next and so on. While a cascading failure can go unnoticed for a long time, the collapse of one highly connected hub may eventually cause a large part of the network to break down (Albert, Jeong \& Barabási, 2000; Barabási, 2003; Watts, 2002).

For example, consider the many concepts in mathematics that are based on the concept of ROTATION. Figure 13 illustrates just some of the domains - from ANGLES to ROOTS OF REAL NUMBERS ${ }^{11}$ - that may be jeopardized if the image schema of ROTATION

${ }^{11}$ Any real number like 1 has 3 complex cube roots. The principal cube root of 1 is $1=1+0 i=(1,0)$. The two non-real cube roots of 1 can be found by repeatedly rotating the line segment from the origin to $(1,0)$ through an angle of $120^{\circ}=360^{\circ} / 3$. 
breaks down. The failure of a critical source domain ripples throughout the metaphoric network. Thus, while scale-free networks are often able to withstand the failure of a number of peripheral nodes, they are susceptible to crippling failures if one of the highly-connected hubs collapses (Barabási, 2003).

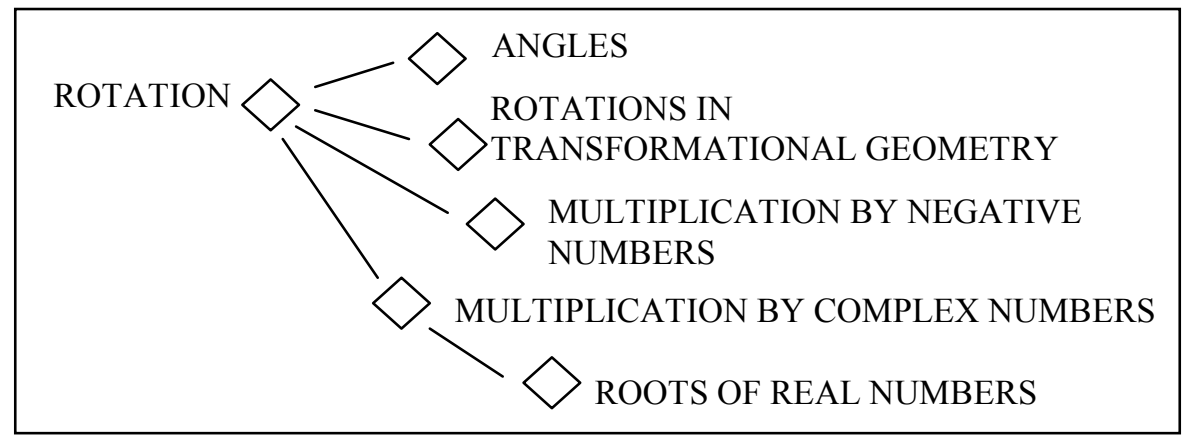

Figure 13: Some concepts metaphorically linked to ROTATION

The field of mathematics has suffered many such crises: in the fifth century B.C., the discovery that the diagonals of squares could not be expressed as ratios of whole numbers caused the Pythagorean theory of proportion to be discarded as unsound, until it was later revised; the field of analysis was threatened by imprecise notions of infinitesimals, which were replaced by the more rigorous concept of LIMIT by Cauchy; and discoveries of paradoxes in Cantor's set theory cast into doubt the validity of the whole foundational structure of mathematics in the early twentieth century (Eves, 1997).

Thus, the scale-free pattern of metaphoric links joining conceptual domains into a network determines dynamic behavior within the structure. Lines of communication go through key mediating nodes, which are powerful, commonly used sources. These hubs serve to connect clusters of related concepts and, ultimately, all nodes in the network. At the same time, such dependence on central nodes puts the network at risk. For if a hub fails, large portions of the network may break down. Those parts of the network that remain are isolated, fragmented, and consequently more vulnerable. The scale-free topology of the proposed metaphoric network of mathematics proves to be both the strength and the weakness of its structure.

\section{Implications for Education}

In this paper, we have attempted to show that the scale-free structure of the network formed by conceptual domains and conceptual metaphors may clarify the nature of the systems of mathematical knowledge at the subjective level and at the level of formal mathematics (the inner and outer nested layers of Figure 1). Since each layer of organization in a complex system has similar structure and dynamics to the others, network theory analysis should, therefore, provide guidance for the learning of mathematics in the classroom and in the organization of mathematics as presented in curricula (the middle two nested layers of Figure 1). 
In particular, we suggest that recognizing events and changes that are characteristic of a scale-free topology has the potential to shed light on causes of students' difficulties in learning and utilizing mathematics. There is some intrinsic credibility to the idea of the vulnerability of nodes and cascading failures. Experience in the classroom leads one to recognize situations where the catastrophic collapse of a student's understanding does occur. A learner may seem to comprehend a mathematical topic well, and then something happens. Perhaps one too many idea is introduced, or some critical piece of background material is shaken, but suddenly the student's understanding of the concept falls apart.

As educators, we believe we have witnessed this in the middle school classroom. By way of specific example, the concept of MULTIPLICATION tends to be constrained by "definitions" of repeated addition and grouping. These interpretations work well for elementary arithmetic, but, when learners encounter multiplication of negative numbers, they lack a key metaphor - MULTIPLICATION BY -1 IS ROTATION BY $180^{\circ}-$ needed to make sense of the new situation. A once well-understood concept is now unclear. We would suggest that the familiar "I was good at math until grade 7" mantra may be, at least in part, attributable to this difficulty.

As discouraging as this is for a teacher to witness, it is even harder to see comprehension of a whole group of related concepts shatter. The student whose understanding of a key idea is limited will inevitably have difficulty with related concepts. As teachers, we have seen the trouble Grade 10 students have comprehending EXPONENTIATION and their consequent problems in working with connected domains such as POLYNOMIALS, QUADRATIC EQUATIONS, and LOGARITHMS. A cascading failure, described previously in theoretical terms, becomes visible in the classroom as it is set in motion by the weakness of a single mathematical concept.

The dynamics that occur in the metaphoric network of mathematics appear to offer some explanation for why students experience these types of difficulties. As a scale-free structure, mathematics is inherently vulnerable because of the crucial role that certain conceptual domains play in ensuring the connectivity of the system. As in other complex systems, some nodes are simply more important than others. It would seem that an inadequate understanding of one of these hubs has the potential to handicap severely a student's comprehension of concepts that are connected to it and, perhaps, of mathematics as a whole.

To increase the robustness of the network of metaphors, attention might be focused on strengthening learners' grasp of major source domains used in mathematical metaphors. There are two difficulties with this approach. First, mathematicians and cognitive scientists have not yet identified which source domains are hubs. Second, teachers can assist students to reinforce their conceptions of key source domains, but this will not eliminate the vulnerability that is characteristic of a scale-free network. Hubs are still hubs.

In order to improve the robustness of the network of metaphors, one must change its structure. There are several ways in which this might be accomplished. Watts (2002) suggests that reducing the number of connections to a hub would lessen the likelihood of 
network failure. He states, "even in the event a hub did fail, fewer [nodes] would be affected, causing the system as a whole to suffer less" (p. 193).

This approach is not one that a mathematics teacher can readily choose; particular concepts are repeatedly selected as source domains because of their usefulness and because the mathematics community has traditionally employed them to develop new concepts. It is not likely that a teacher would deliberately refuse to use domains that do provide a coherent structure for developing mathematical knowledge, nor would this be responsible.

It would seem that another approach is required. Increasing the number of connections among conceptual domains would have the desired effect of reducing the network's dependence on its hubs. Adding even a few links between clusters of nodes decreases the network's vulnerability. The more distributed structure that results has sufficient redundancy to ensure that "even if some nodes [go] down, alternative paths [maintain] the connections between the rest of the nodes" (Barabási, 2003, p. 144).

Using metaphors linked to traditional sources in the development of a concept is necessary; such connections are strong because they are widely used and constantly reinforced. However, teachers can introduce new connections from different domains to assist learners in constructing a more robust network of concepts. Then if a student's understanding of a single domain fails, he or she can rely instead on metaphors projecting inferential structure from other conceptual areas. Newly developed links to existing conceptual domains will necessarily be less well established than traditional connections, but such weak links play a key role in tying a network together (Barabási, 2003; Buchanan, 2002; see Figure 14). By serving as "bridges" between different segments of the network, they provide the shortcuts that both reduce the number of connections in a path between two nodes and decrease the possibility that a network will become fragmented. Following a tenet of complex dynamics, even these small changes can make a tremendous difference to the dynamics and robustness of the network.

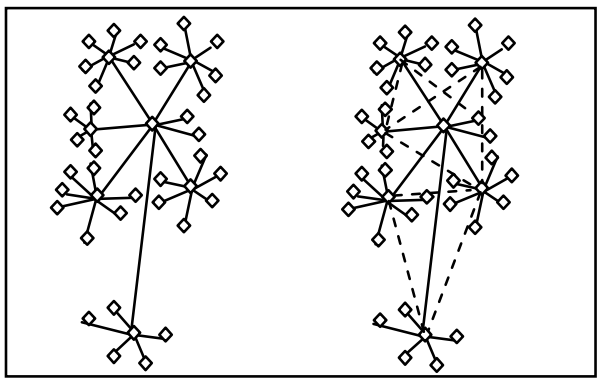

Figure 14: Decreased dependence on a central node as a result of adding a few weak links to a scale-free network

Support for this approach can be found in recent studies in mathematics education (although the work does not refer explicitly to network theory). Tall (2003) stated that the automatic use of previously learned metaphors for arithmetic could cause confusion for students. He described how young children felt that adding two numbers should always yield a larger sum. This perception is justified if one is using the ARITHMETIC IS OBJECT 
COLLECTION metaphor, but the OBJECT COLLECTION source domain cannot deal with situations where the addition of integers leads to smaller sums ( $2+-7$ makes -5$)$. Moses and Cobb (2001) found the same reliance on the ARITHMETIC IS OBJECT COLLECTION metaphor. They felt that ARITHMETIC IS MOTION ALONG A PATH would be more useful in this context and developed activities using experiences familiar to students, like riding on the subway, to strengthen this metaphor. With such techniques, they were successful in improving children's understanding of integer arithmetic.

Davis and Simmt (2006) recently completed a study of teachers' understanding of the concept of MULTIPLICATION. While the most common definition for MULTIPLICATION given in primary textbooks is that of repeated addition ( $3 \times 4=4+4+$ 4 ), participants were able to identify a large cluster of different representations (see Figure 15). Teachers in the study realized that MULTIPLICATION did not have a single meaning, but was the target of many source domains, revealed by the images, actions, and analogies they listed. Moreover, they concurred that if learners were made aware of these multiple interpretations, they would be able to appreciate why MULTIPLICATION is used in so many diverse contexts.

Multiplication is ...

- repeated addition: e.g., $2 \times 3=3+3$ or $2+2+2$;

- equal grouping: e.g., 2 x 3 can mean "2 groups of 3";

- number-line hopping: e.g., 2 x 3 can mean "make 2 hops of length 3", or "3 hops of length 2";

- sequential folding: e.g., $2 \times 3$ can refer to the action of folding a page in two and then folding the result into 3 ;

- many-layered (literal meaning of 'multiply'): e.g., 2 x 3 means "2 layers, each of which contains 3 layers";

- ratios and rates: e.g., $3 \mathrm{~L}$ at $\$ 2 / \mathrm{L}$ costs $\$ 6$;

- array-generating: e.g., 2 x 3 gives you 2 rows of 3 or 2 columns of 3;

- area-producing: e.g., a 2 unit by 3 unit rectangle has an area of 6 units $^{2}$;

- dimension-changing;

- number-line stretching or compressing: e.g., 2 × $3=6$ can mean that "3

Figure 15: Different representations of MULTIPLICATION (Davis \& Simmt, 2006)

These three studies identify the importance of adding metaphoric connections to a concept. ADDITION can be linked to many diverse sensory perceptions. Lakoff and Núñez (2000) suggest that four grounding metaphors (ARITHMETIC AS OBJECT COLLECTION, ARITHMETIC AS OBJECT CONSTRUCTION, THE MEASURING STICK METAPHOR and ARITHMETIC AS MOTION ALONG A LINE) are needed to fully capture the many qualities of ADDITION in different contexts. Similarly, the different representations of MULTIPLICATION (Davis \& Simmt, 2006) enrich that conceptual domain. These varied interpretations link MULTIPLICATION to the image schemas upon which these four grounding metaphors are based (see Figure 16). 


\begin{tabular}{|c|c|c|c|}
\hline OBJECT & OBJECT & MEASURING & MOTION \\
\hline COLLECTION & CONSTRUCTION & STICK & ALONG A LINE \\
\hline $\begin{array}{l}\text { repeated addition } \\
\text { equal grouping } \\
\text { many-layered }\end{array}$ & $\begin{array}{l}\text { repeated addition } \\
\text { sequential folding } \\
\text { array generating } \\
\text { area producing }\end{array}$ & repeated addition & $\begin{array}{l}\text { repeated addition } \\
\text { number line hopping } \\
\text { number line stretching }\end{array}$ \\
\hline
\end{tabular}

Figure 16: Interpretations of MULTIPLICATION linked to the four grounding metaphors

A conceptual domain actively contributes to an individual's understanding only when a threshold number of nodes are activated (Lamb, 1999). If a concept is connected to only one key source in the network that represents a student's understanding and that hub fails, then the cluster of nodes that would be transplanted from the hub's subnetwork to that of the target will not be available. Consequently, the threshold of activation for the target domain may not be met. We suggest that by creating a variety of links from different source domains to the concept, there is less chance that this will occur. Although nodes corresponding to properties of one source may remain dormant, other nodes associated with different sources would still be available for activation. Therefore, increasing the number of domains to which a concept is connected should improve the robustness of an individual's knowledge.

In the metaphoric network of mathematics, weak links are created by developing new conceptual metaphors among domains. We suggest, therefore, that introducing a variety of metaphors in classroom activities to provide inferential structure for as many aspects of a concept as possible is vital for the establishment of such new connections, and for ensuring rich and complex subnetworks for mathematical ideas. If concepts are not dependent on the strength of a single key source domain, then the network of metaphors that constitutes a student's understanding of mathematics will become more robust and not subject to the fragmentation and cascading failures characteristic of scalefree networks. "If our mathematical conceptions are to be sound and stable, they must stand on more than one metaphorical leg" (Sfard, 1997, p. 367).

How can educators assist students to construct these metaphorical legs? Teachers could orient instruction around a variety of metaphors when exploring a new idea or extending a previously encountered one. One might not want to introduce multitudes of metaphors all at once, for students would likely find this confusing. But over the course of the class or unit, teachers could ensure that a number of different metaphoric approaches are used. These metaphors need to be chosen carefully; it is important that the source domains are familiar to students and that they accurately reflect some aspect of the structure of the target domain (Chiu, 2001). Thus, useful classroom activities could bolster learners' understanding of appropriate source domains or reinforce the particular correspondences that exist between these sources and the target. When established, a conceptual metaphor is used unconsciously and automatically (Lakoff \& Núñez, 2000), but before this can happen, students need sufficient experience working with it. 
Teachers can provide the activities, images, models, and explanations that would make this possible.

Each metaphor has its limitations and its strengths. Learners may not understand everything that is implicit in a metaphor - what it is, what it hides, and what it introduces. Making discussion of metaphors an explicit part of classroom discourse may make these points clearer. Teachers might draw attention to the use of metaphoric terms, notations and images, and students could be encouraged to discuss the associations these bring to mind. As learners are likely to understand a metaphor in terms of personal experience (Pimm, 1987), there is need to make its mathematical interpretation clear. Teachers could invite students to identify features in the source that correspond to aspects of the target domain and to articulate how various metaphors are different and similar. Such discussion might clarify the need for more than one metaphor in understanding a concept and might help learners realize which metaphors are appropriate for use in particular situations. Social interaction has been shown to be important in determining the efficacy and usefulness of patterns of metaphoric thought in the classroom (Madden, 2001).

Closer examination of the ways in which students use conceptual metaphors may assist teachers to identify an individual's misconceptions of mathematical ideas. Learners may base their reasoning on a source domain that does provide appropriate inferential structure for a target domain may provide "an ambiguous (and potentially deceitful) impetus with which to make sense" (Sinclair \& Schiralli, 2003, p. 85). Students, too, may hang on to "a concrete metaphor that refuses to die" (Sfard, 1997, p. 368), not making the necessary transition to using more abstract domains as sources. These kinds of links may have to be weakened, if not broken, and supplanted by more suitable connections.

Different metaphors have their own inferential structure and can "lead to different conscious and unconscious beliefs that can cause obstacles to drawing various aspects [of a target domain] into a central core concept" (Watson, Spyrou \& Tall, 2003). As Núñez, Edwards and Matos (1999) point out in their study of conflicting metaphors used in the study of continuity of functions, although both metaphors are reflected in similar, even identical terminology, students are seldom told that these links have a completely different embodied foundation. Special efforts are needed to integrate different inferential structures into a coherent whole.

Before these suggestions can be implemented, there is a need for professional development to help teachers understand the important role conceptual metaphors play in cognition and to assist them in developing a repertoire of teaching strategies that would enable the effective introduction and use of metaphors in classrooms. Assistance is also needed to increase teachers' knowledge of the many metaphors that connect mathematical concepts together. This is not easy, for metaphoric structures have not been studied extensively and identification of metaphors requires sensitive attention to language, gestures, images, applications, and analogies. The complex meanings of mathematical concepts are "constructed on the basis of scattered cues and sustained innuendo" (Kimmel, 2002, p. 518). Providing opportunities for a more stable understanding of mathematics requires teachers to pick up on these subtle hints, to 
identify the underlying metaphors and to share them with students. Before this can happen, however, more needs to be known about the many metaphors that constitute the network of mathematics.

There are so many conceptual metaphors linking multitudes of mathematical domains that it is critical to know just what they are and how they function. Some progress has been made. In the field of cognitive science, some researchers try to clarify the precise nature of mathematical concepts (cf., Lakoff \& Núñez, 2000). A thorough analysis of mathematical ideas that explicates what the structure of each conceptual domain is, showing how it is ultimately grounded, and that elucidates what the network of metaphors in mathematics looks like would be desirable. Without this information, it is difficult to imagine teachers and learners interpreting mathematical ideas as complex systems knitted together by metaphorical reasoning. Designing classroom activities to enable students to construct their understanding of mathematical concepts using inferential structures conveyed by clusters of metaphors would be equally difficult. Only by becoming cognizant of the many connections between conceptual domains can a new way of understanding what mathematics is be generated and introduced into the classroom.

Once sufficient progress has been made on this "mathematical idea analysis" (Lakoff \& Núnez, 2000, p. 29), a reconceptualization of curriculum structures would seem desirable. Current programs of study focus on mathematical topics, arranging them in an essentially linear fashion. Mathematics is presented as a hierarchical structure, with concepts at each level being built on those taught in previous grades. Students accumulate a collection of techniques to use in prescribed ways.

This presentation of mathematics inevitably conflicts with what network theory reveals about mathematical knowledge and mathematical understanding. The structure of mathematics is more akin to an ecosystem, rather than a tower of ideas. Concepts are important, but the connections between them are even more vital; it is the metaphoric links in mathematics that determine a concept's inferential structure, connect it to clusters of mathematically associated concepts, and ensure its stability. Programs of study should highlight multiple interpretations of mathematical concepts at each level and curriculum documents should mandate that teachers emphasize these in instruction. More importantly, a syllabus should actively encourage teachers to incorporate different metaphoric representations than those explicitly included in programs of study or authorized texts. Without changes to curriculum, trying to make use of the metaphoric network structure of mathematics in instruction is not likely to be successful.

\section{Conclusion}

In this paper, we posit that since mathematics, considered as a system of concepts, exhibits the properties of complex systems identified by Cilliers (1998), it is therefore appropriate to consider this system of mathematical ideas as a network structure. We have further suggested that the theory of embodied mathematics provides a possible structure for a network of mathematical knowledge, where conceptual domains 
represent nodes in the network and conceptual metaphors provide the links between them. Network analysis provides evidence that this interpretation of mathematical knowledge is suitable, as the metaphoric network of mathematics displays the nested forms and scale-free topology that are typical of complex systems.

Thus, network analysis of this structure may offer fresh insights into the nature of mathematical knowledge, both for an individual's personal understanding of mathematics and for mathematics as a formal field of study (the inner and outer nested layers of Figure 1). In particular, the scale-free structure of mathematical knowledge determines the nature and behavior of the metaphoric network. Mathematics consists of a large number of concepts whose meanings are determined by their interrelationships. These connections tend to involve key source domains, the hubs of the network. These hubs ensure that every concept in mathematics is ultimately linked to every other idea in the network, but they may also compromise the robustness of its structure. If a concept that many other ideas are based on is found to be in error, or if understanding of that domain falters, then mathematical knowledge may become fragmented, with links no longer existing between some concepts and increased vulnerability in the system. Network theory also suggests that constructing additional metaphoric links among concepts reduces dependence on these key source domains and thereby strengthens the overall structure of mathematics.

Since each level in a system of nested forms both enable and constrains the others, these perceptions should provide mathematics educators with valuable guidance for the generation of collective knowledge in classrooms and in the organization of mathematical knowledge as portrayed in curricula (the two middle layers of Figure 1). Ways of strengthening learners' conceptualizations of mathematical ideas by ensuring concepts have metaphoric links to multiple source domains have been proposed. Curricular changes to support this strategy have been suggested. Attending to what is known of the dynamics of complex systems, our hope would be that these ideas are useful for ongoing cyclical elaborations of school mathematics and pedagogical practice.

We suspect that the significance of network theory extends into the pedagogy of other disciplinary fields. We believe that it may also assist in understanding the dynamics of other sorts of systems involved in schooling, such as classroom collectives and programs of study. In other words, our speculations may be only a beginning of an important complex conversation in education.

\section{References}

Albert, R., Jeong, H., and Barabási, A. L. (2000). Attack and error tolerance of complex networks. Nature. 406: 378-382.

Barabási, A. L. (2003). Linked: How everything is connected to everything else and what it means for business, science, and everyday life. New York: Plume.

Barabási, A. L. and Albert, R. (1999). Emergence of scaling in random networks. Science. 286: 509-512.

Barabási, A. L., Albert, R., Jeong, H. and Bianconi, G. (2000). Power-law distribution of the World Wide Web. Science. 287: 2115a.

Bell, E. T. (1945). The development of mathematics. New York: McGraw-Hill. 
Bianconi, G. and Barabási, A. L. (2001). Competition and multiscaling in evolving networks. Europhysics Letters. 54 (4): 436-442.

Boyer, P. (1994). The naturalness of religious ideas: a cognitive theory of religion. Berkeley, CA: University of California Press.

Broder, A., Kumar, R., Maghoul. F., Raghavan, P., Rajagopalan, S., Strata, R., Tomkins, A. and Wiener, J. (2000). Graph structure in the web. Computer Networks. 22: 309-320.

Buchanan, M. (2002). Nexus: Small worlds and the groundbreaking theory of networks. New York: Norton.

Cajori, F. (1896). A history of elementary mathematics with hints on methods of teaching. New York: Macmillan.

Chiu, M. M. (2000). Metaphorical reasoning: Origins, uses, development and interactions in mathematics. Education Journal. 28 (1): 14-46.

Chiu, M. M. (2001). Using metaphors to understand and solve arithmetic problems: Novices and experts working with negative numbers. Mathematical Thinking and Learning. 3 (2/3): 93-124.

Cilliers, P. (1998). Complexity and postmodernism: Understanding complex systems. London: Routledge.

Cooney, T. and Wiegel, H. (2003). Examining the mathematics in mathematics teacher education. In A. Bishop, M. Clemens, C. Keitel, J. Kilpatrick and F. Leung (Eds.), Second international handbook of mathematics education: Vol. 2 (pp. 795-828). Dordrecht: Kluwer.

Danziger, K. (1990). Generative metaphor and the history of psychological discourse. In D. E. Leary (Ed.), Metaphors in the history of psychology (pp. 331-356). Cambridge, UK: Cambridge University Press.

Davis, B. and Simmt, E. (2006). Mathematics-for-teaching: An ongoing investigation of the mathematics that teachers (need to) know. Educational Studies in Mathematics. 61 (3): 293-319.

Edelman, G. M. (1987). Neural Darwinism: The theory of neuronal group selection. New York: Basic Books.

English, L. D. (1997). Analogies, metaphors, and images: Vehicles for mathematical reasoning. In L. D. English (Ed.), Mathematical reasoning: Analogies, metaphors, and images (pp. 3-18). Mahwah, NJ: Lawrence Erlbaum Associates.

Eves, H. (1997). Foundations and fundamental concepts of mathematics (3rd ed.). Mineola, NY: Dover.

Fauconnier, G. and Turner, M. (1998). Conceptual integration networks. Cognitive Science. 22 (2): $133-$ 187.

Grabiner, J. (1998). Is mathematical truth time-dependant? . In T. Tymoczko (Ed.), New directions in the philosophy of mathematics: An anthology (revised and expanded edition), pp. 201-215. Princeton, NJ: Princeton University Press.

Hersh, R. (1998). Some proposal for reviving the philosophy of mathematics. In T. Tymoczko (Ed.), New directions in the philosophy of mathematics: An anthology (revised and expanded edition), pp. 929. Princeton, NJ: Princeton University Press.

Johnson, M. (1987). The body in the mind: The bodily basis of meaning, imagination, and reason. Chicago: University of Chicago Press.

Johnson, S. (2001). Emergence: The connected lives of ants, brains, cities, and software. New York: Scribner.

Kelly, K. (1994). Out of control: The new biology of machines, social systems, and the economic world. Cambridge, MA: Perseus.

Kimmel, M. (2002). Metaphor, imagery, and culture: Spatialized ontologies, mental tools, and multimedia in the making. Unpublished doctoral dissertation. Vienna: Department of Philosophy, University of Vienna.

Kövacses, Z. (2002). Metaphor: A practical introduction, Oxford, UK: Oxford University Press.

Lakoff, G. (1987). Women, fire and dangerous things: What categories reveal about the mind. Chicago: University of Chicago Press.

Lakoff, G. (1993). The contemporary theory of metaphor. In A. Ortony (Ed.), Metaphor and thought (2nd ed.). Cambridge, UK: Cambridge University Press.

Lakoff, G. and Johnson, M. (1980). Metaphors we live by. Chicago: University of Chicago Press. 
Lakoff, G. and Johnson, M. (1999). Philosophy in the flesh: The embodied mind and its challenge to western thought. New York: Basic Books.

Lakoff, G. and Núñez, R. (2000). Where mathematics comes from: How the embodied mind brings mathematics into being. New York: Basic Books.

Lamb, S. (1999). Pathways of the brain: The neurocognitive basis of language. Amsterdam: John Benjamin.

Machtinger, D. D. (1965). Experimental course report: Kindergarten. (Report No. 2, July, 1965). Webster Groves, MO: The Madison Project.

Madden, J. (2001). Review of "Where mathematics comes from: How the embodied mind brings mathematics into being". Notices of the American Mathematical Society. 48 (10): 1182-1188.

Mazur, B. (2003). Imagining numbers (particularly the square root of minus fifteen). New York: Farrar Straus Giroux.

Meisner, M. (1992). Metaphors of nature: Old vinegar in new bottles? Trumpeter. 9 (4). Retrieved March 11, 2005, from http://trumpeter.athabascau.ca/content/v9.4/meisner.html

Moses, R. P. and Cobb, C. E. (2001). Radical equations: Math literacy and civil rights. Boston: Beacon Press.

Newman, M., Barabási, A. L. and Watts, D. (2006). The structure and dynamics of networks. Princeton: Princeton University Press.

Núñez, R. (2004). Do real numbers really move? Language, thought, and gesture: The embodied cognitive foundations of mathematics. In F. Iida, R. Pfeifer, L. Steels and Y. Kuniyoshi (Eds.), Revised Selected Papers of the International Seminar on Embodied Artificial Intelligence (pp. 54-73). Berlin: Springer.

Núñez, R., Edwards, L. and Matos, J.P. (1999). Embodied cognition as grounding for situatedness and context in mathematics education. Educational Studies in Mathematics. 39: 45-65.

O'Connor, J. J. and Robertson, E. F. (2000). Jean Robert Argand. MacTutor History of Mathematics. Retrieved January 25, 2007, from http://www-history.mcs.st-andrews.ac.uk/Biographies/ Argand.html

Pickering, A. (1995). The mangle of practice: Time, agency, and science. Chicago: University of Chicago Press.

Pimm, D. (1987). Speaking mathematically: Communication in mathematics classrooms. London: Routledge \& Kegan Paul.

Presmeg, N. (1992). Prototypes, metaphors, metonymies, and imaginative rationality in high school mathematics. Educational Studies in Mathematics. 23 (6): 595-610.

Presmeg, N. C. (1997). Reasoning with metaphors and metonymies in mathematical learning. In L. D. English (Ed.), Mathematical reasoning: Analogies, metaphors and images (pp. 267-280). Mahwah, NJ: Lawrence Erlbaum.

Rotman, B. (2000). Mathematics as sign: Writing, imagining, counting. Stanford, CA: Stanford University Press.

Rumelhart, D. E. and McClelland, J. L. (1986). Parallel distributed processing: Explorations in the microstructure of cognition, 2 vols. Cambridge, Mass: MIT Press.

Sfard, A. (1994). Reification as the birth of metaphor. For the Learning of Mathematics. 14 (1): 44-55.

Sfard, A. (1997). Commentary: On metaphorical roots of conceptual growth. In L. D. English (Ed.), Mathematical reasoning: Analogies, metaphors, and images (pp. 339-371). Mahwah, NJ: Lawrence Erlbaum Associates.

Sinclair, N. and Schiralli, M. (2003). A constructive response to "Where mathematics comes from". Educational Studies in Mathematics. 52: 79-91.

Stewart, I. (1998). Life's other secret: The new mathematics of the living world. London: Penguin.

Struik, D. (1987). A concise history of mathematics. New York: Dover.

Tall, D. O. (2003). Mathematical growth: From child to mathematician. Retrieved November 22, 2005, from http://www.tallfamily.co.uk/david/mathematical-growth/

Thurston, W. P. (1994). On proof and progress in mathematics. Bulletin of the American Mathematical Society. 30 (2): 161-177. 
Travers, M. (1996). Programming with agents: New metaphors for thinking about computation. Unpublished doctoral dissertation, MIT. Retrieved February 23, 2006, from http://xenia.media.mit.edu/ $\sim \mathrm{mt} /$ thesis/mt-thesis-2.1.html

Watson, A., Spyrou, P. and Tall, D. (2003). The relationship between physical embodiment and mathematical symbolism: The concept of vector. The Mediterranean Journal of Mathematics Education. 1 (2): 73-97.

Watts, D. (2002). Six degrees: The science of a connected age. New York: W.W. Norton.

Watts, D. and Strogatz, S. (1998). Collective dynamics of "small-world" networks. Nature. 393: 440-442.

\title{
Acknowledgments
}

Versions of this paper were presented at the Fourth Conference on Complexity Science and Educational Research, February 2007, Vancouver, British Columbia, Canada (published in the proceedings pp. 165176) and the First Conference of the Mathematics Education Graduate-Students Association, November 2008, Edmonton, Alberta, Canada. Portions were published as an article entitled "Making connections: Mathematical understanding and network theory" in For the Learning of Mathematics (2009, vol. 28, no. 3, pp. 20-27). The work is based on E. Mowat's dissertation entitled Making Connections: Network Theory, Embodied Mathematics, and Mathematical Understanding.

\begin{abstract}
About the Authors
Elizabeth Mowat is a former teacher of mathematics and a recent graduate of the doctoral program at the University of Alberta in the Department of Secondary Education. Research interests are complexity science, cognition in mathematics, and exponentiation. Her dissertation Making Connections: Network Theory, Embodied Mathematics, and Mathematical Understanding is available at http://hdl.handle.net/10048/853 Email: emowat@ualberta.ca
\end{abstract}

Brent Davis is Professor and Distinguished Research Chair in Mathematics Education at the University of Calgary. His research is developed around the educational relevance of developments in the cognitive and complexity sciences, and he teaches courses at the undergraduate and graduate levels in curriculum studies, mathematics education, and educational change. Davis has published books and articles in the areas of mathematics learning and teaching, curriculum theory, teacher education, epistemology, and action research. His most recent book is Engaging Minds: Changing Teaching in Complex Times ( $2^{\text {nd }}$ edition, 2008; co-authored with Dennis Sumara and Rebecca Luce-Kapler). Email: brent.davis@ucalgary.ca

(C) Copyright 2010. The authors, ELIZABETH MOWAT \& BRENT DAVIS assign to the University of Alberta and other educational and non-profit institutions a non-exclusive license to use this document for personal use and in courses of instruction provided that the article is used in full and this copyright statement is reproduced. The authors also grant a non-exclusive license to the University of Alberta to publish this document in full on the World Wide Web, and for the document to be published on mirrors on the World Wide Web. Any other usage is prohibited without the express permission of the authors. 